\title{
Analisis Manajemen Risiko Pada Layanan Pengunduran Diri Mahasiswa Menggunakan Framework COBIT 5 Fokus Pada Mengelola Risiko (APO12)
}

\author{
Riki Nurhidayat ${ }^{\mathrm{a}, 1}$, Sri Handayaningsih ${ }^{\mathrm{b}, 2}$ \\ ${ }^{a}$ Teknik Informatika Universitas Ahmad Dahlan, Jl. Ringroad Selatan, Bantul, Yogyakarta 55191, Indonesia \\ ${ }^{\mathrm{b}}$ Sistem Informasi Universitas Ahmad Dahlan, Jl. Ringroad Selatan, Bantul, Yogyakarta 55191, Indonesia \\ ${ }^{1}$ Riki.nurhidayat07@gmail.com; ${ }^{2}$ sriningsih@tif.uad.ac.id
}

\begin{abstract}
ABSTRAK
Perguruan tinggi sebagai salah satu institusi pendidikan adalah suatu lembaga yang memberikan pelayanan publik yang mengharuskan untuk menjaga kualitas pelayanan bagi para stakeholdernya agar tetap menjadi pilihan utama di masyarakat. Terdapat suatu lemabaga atau biro yang mempunyai tugas utama yaitu mengelola layanan akademik dan mengelola data transaksi akademik yaitu Biro Akademi dan Admisi (BAA). Kegitatan akademik yang ada diatur dalam Standard Operasional Procedural (SOP), dan salah satunya adalah layanan pengunduran diri mahasiswa. Layanan ini sudah berjalan sesuai dengan SOP namun dari hasil wawancara dan observasi ditemukan risiko terhadap layanan ini, yaitu: kurangnya penyampaian informasi mengenai alur pengunduran diri, terhambatnya aktivitas yang disebabkan oleh persyaratan dalam pemenuhan surat bebas (laboratorium, persputakaan, keuangan) yang diperoleh dari tempat yang berbeda, sulitnya memperoleh persetujuan (penasehat akademik, Kaprodi dan Dekan) dikarenakan ketidakhadirannya di perguruan tinggi dan juga akan mempengaruhi skor dalam penilaian akreditasi apabila risiko pada layanan ini tidak dilakukan penanganan. Rancangan model manajemen risiko dibuat dengan metode Control Objective for Information and Related Technologi (COBIT) 5 pada Proses APO12 (Manage Risk). Pengumpulan data dilakukan dengan menyebar kuisioner kepada responden yang ada di perguruan tinggi kemudian diukur prosentase dari masing-masing pertanyaan, hasil pengukuran dianalisis untuk mencari risiko dan dampak yang ditimbulkan serta penilaian untuk menentukan kategori (high, medium, low) terhadap temuan risiko, setelah itu dilakukan pengelolaan risiko untuk mencegah agar risiko tidak mencapai kategori tinggi (high). Dari hasil uji model manajemen risiko menunjukan bahwa model tersebut dapat diimplementasikan dan mendukung organisasi dalam meningkatkan (improvement) pelayanan.
\end{abstract}

Ciptaan disebarluaskan di bawah lisensi CC-BY-SA.

Kata kunci: Analisis, Manajemen Risiko, COBIT 5, Pengunduran diri mahasiswa

\section{Pendahuluan}

Perguruan tinggi sebagai salah satu institusi pendidikan adalah suatu lembaga yang memberikan

pelayanan public. Persaingan antar perguruan tinggi yang semakin ketat membuat perguruan tinggi harus menjaga kualitas pelayanan bagi para stakeholdernya (Mahasiswa, calon Mahasiswa, dan alumni) agar tetap menjadi pilihan utama di masyaraka[1]. Diperguran tingi terdapat suatu lembaga atau biro yang mempunyai tugas utama yaitu mengelola layanan akademik dan mengelola data transaksi akademik yaitu Biro Akademi dan Admisi (BAA). Kegitatan akademik yang ada diatur dalam suatu Standard Operasional Procedural (SOP), dan salah satunya adalah layanan pengunduran diri mahasiswa.

Pengunduran diri adalah pemberhentian kegiatan akademik yang dikeluarkan oleh Rektor atas permintaan mahasiswa. Proses dalam pengunduran diri yaitu mahasiswa mengisi form permohonan diri dan melengkapi persyaratan di BAA, kemudian Rektor menerbitkan SK 
pengunduran diri. Berdasarkan hasil observasi dan wawancara, layanan ini sudah berjalan seperti yang tertuang dalam SOP namun diperoleh beberapa risiko atau ancaman yaitu: mahasiswa dalam melakukan pengajuan permohonan pengunduran diri harus memenuhi beberapa persyaratan dan salahsatunya adalah surat bebas (perpustakaan, laboratorium, dan keuangan SPP) yang harus diperoleh dari tempat yang berbeda. Selain itu surat permohonan pengunduran yang harus ditandatangani atau validasi oleh dosen pembimbing akademik, Kaprodi, dan Dekan akan tetapi karena kemungkinan tidak adanya pihak tersebut di perguruan tinggi akan menyebabkan terhambatnya dan tertundanya proses pengajuan permohonan pengunduran diri. Kurangnya informasi yang diterima mahasiswa mengenai tahapan untuk mengundurkan diri sehingga tidak tercapainya pengunduran diri yang sesuai dengan prosedur. Terdapat beberapa mahasiswa yang mengundurkan diri hanya sampai tingkat fakultas atau proses pengunduran diri tidak berjalan sepenuhnya seperti yang tertuang dalam SOP, sehingga mengakibatkan mahasiswa dinyatakan keluar tanpa memperoleh surat SK dari Rektor. Apabila mahasiswa mengundurkan diri tidak sesuai dengan prosedur meningkat maka akan berpengaruh terhadap penilaian (skor) akreditasi perguruan tinggi.

Untuk mencapai tingkat kepuasan tinggi bagi universitas maupun perusahaan, diperlukan adanya pemahaman tentang apa yang diinginkan oleh konsumen yang ada dalam lembaga untuk memenuhi kebutuhan konsumen yang bersangkutan[1]. Hal ini mengidentifikasikan bahwa untuk tercapainya layanan pengunduran diri yang optimal, efektif dan efisien diperlukan adanya pelayanan yang baik dan tanggapan yang cepat dimulai dari pengajuan surat, pemenuhan persyaratan, validasi, sampai dengan mahasiswa telah mengundurkan diri. Berdasarkan hal diatas, untuk menghindari penurunan tingkat optimalnya suatu layanan dan tingkat kepuasan stakeholdernya terhadap perguruan tinggi, maka perlu dilakukan pengamatan dengan pembuatan model manajemen risiko terhadap layanan tersebut, yang diharapkan mampu mengurangi dan mencegah perguruan tinggi dari kegagalan pada penerapan proses pengunduran diri.

\section{Kajian Pustaka}

\subsection{Kajian Terdahulu}

Berdasarkan penelitian terdahulu yang berjudul "Pengukuran Tingkat Kesuksesan Sistem Informasi Akademik Universitas XYZ Dengan Model Delone Dan McLean" yang disusun oleh Amri Ahmad dam Sri Handayaningsih. Penelitian ini bertujuan untuk mengukur sejauh mana tingat kesuksesan sistem informasi akademik.

Penelitian ini juga mengacu pada skripsi yang berjudul "Pembuatan Manajemen Risiko Pada Pengelolaan Infrastruktur TI Menggunakan Frameowrk COBIT 5 Di Biskom UAD “ yang disusun oleh Nurfadlun. Penelitian ini dilakukan untuk mengetahui risiko pada kondisi saat ini serta untuk mencari tingkat kematangan bidang pengelolaan infrastruktur TI. Model manajemen risiko dibuat untuk mengurangi atau menghilangkan risiko sehingga risiko tidak berdampak buruk bagi bidang ini.

Selain itu juga mengacu pada skripsi yang berjudul "Evaluasi Tata Kelola Teknologi Informasi Menggunakan Framework Cobit 5 Fokus Pada Proses Manage Relationship APO08" yang disusun oleh Rizka Fajrin. Penelitian ini dilakukan untuk mengevaluasi tata kelola TI guna meningkatkan TI sebagai sarana yang berperan penting dalam organisasi.

\subsection{Analisis}

Analisis adalah rangkaian kegiatan pemikiran logis, rasional, sistematis dan objektif dengan menerapkan metodologi atau teknik ilmu pengetahuan, untuk melakukan pengkajian penelaahan, penguraian, perincian, dan pemecahan terhadap objek atau sasaran sebagai salah satu kebulatan komponen yang utuh ke dalam sub komponen-sub komponen yang lebih kecil[1].

\subsection{Risiko dan Manajemen Risiko}

Definisi risiko menurut The Oxford English Dictionary adalah 'A chance or possibility of danger, loss, injury, or other adverse consequences' [6]. Dan definisi at risk atau berisiko dari sumber yang sama adalah 'exposed to danger' [6]. Dalam konteks ini risiko selalu dikaitkan dengan konsekuensi negatif namun menghadapi atau mengambil risiko juga dapat menghasilkan dampak positif. Kemungkinan lainnya risiko bisa berujung pada konsekuensi yang tidak dapat dipastikan. Seihingga risiko dapat didefinisikan "the adverse impact on probability of several 
distinct of uncertainty", atau diartikan sebagai ketidakpastian yang ditimbulkan oleh adanya perubahan[3]. Menurut ISO Guide 73 BS31100 manajemen risik adalah aktivitas yang terkoordinasi untuk mengarahkan dan mengendalikan organisasi dari hal-hal yang berkaitan dengan risiko. Institute of Risk Management (IRM) mendefinisikan manajemen risiko sebagai proses yangbertujuan untuk membantu organisasi memahami, menilai dan mengambil tindakan pada semua risiko dengan maksud untuk meningkatkan kemungkinan keberhasilan dan mengurangi kemungkinan kegagalan. HM Treasury menjelaskan manajemen risiko sebagai semua proses yang terlibat dalam mengidentifikasi, menilai, dan mempertimbangkan risiko, menetapkan kepemilikan, mengambil tindakan untuk mengurangi atau mengantisipasi risiko, dan pemantauan dan peninjauan kemajuan.[5]

\subsection{Proses Bisnis Pengunduran Diri Mahasiswa}

Proses bisnis adalah suatu kumpulan aktivitas atau pekerjaan terstruktur yang saling terkait untuk menyelesaikan suatu masalah tertentu. Suatu proses bisnis dapat dipecah menjadi beberapa sub proses yang masing-masing memiliki atribut sendiri tapi juga berkontribusi untuk mencapai tujuan dari suatu proses. Sehingga proses bisnis pengunduran diri adalah serangkaian aktivitas yang dilakukan mahasiswa untuk mengundurkan diri dari perguruan tinggi. Proses bisnis ini dibuat berdasarkan Standard Operasional Procedural (SOP)[1].

\subsection{COBIT 5}

COBIT (Control Objectives for Information and Related Technology) merupakan kerangka kerja tata kelola TI dan set alat pendukung yang memungkinkan manajer untuk menjembatani kesenjangan/ celah diantara kebutuhan control, masalah teknis dan risiko bisnis. COBIT 5 membantu perusahaan menciptakan nilai optimal dari TI dengan cara menjaga keseimbangan antara mendapatkan keuntungan dan mengoptimalkan tingkat risiko dan penggunaan sumber daya. COBIT 5 memungkinkan TI untuk dikelola dan diatur dalam cara yang lebih menyeluruh untuk seluruh lingkup perusahaan, meliputi seluruh lingkup bisnis dan lingkup area fungsional TI, dengan mempertimbangkan kepentingan para stakeholder internal dan eksternal yang berhubungan dengan TI[3]. Terdapat beberapa komponen cobit, namun dalam penelitian ini menggunakan COBIT domain APO (Align Planand Organize) pada proses Manage Risk (APO12). Proses APO12 merupakan proses yang berfokus pada strategi terbaik untuk mencapai tujuan dan sasaran perusahan dengan memperhatikan bentuk dan infrastruktur oranisasi guna mencapai hasil yang optimal dan memberikan manfaat dari penggunaan TI yang secara terus menerus mengidentifikasi, menilai, dan mengurangi risiko yang berubungan dengan TI didalam toleransi yang ditemukan oleh manajemen perusahaan[7].

\section{Metode Penelitian}

Pada penelitian ini metode yang digunakan adalan kerangka kerja (Framework) COBIT 5 domain APO (Align Planand Organize) proses APO12 (Manage Risk). Tujuan dari APO12 adalah mengintegrasi manajemen dari risiko perusahaan sehingga risiko dapat diminimalkan atau bahkan dihilangkan. Metode pengumpulan data dilakukan dengan observasi, wawancara, studi pustaka, dan survey dengan penyebaran kuisioner terkait isu-isu risiko pada layanan pengunduran diri mahasiswa. Kuisioner dibuat dengan acuan proses APO12 dengan aktivitas-aktivitas didalamnya yaitu Collect Data, Analysis Risk, Articulate Risk, Maintain a Risk Profile Articulate Risk, dan terakhir Define a Risk Management Action Portofolio[7]. Selanjutnya hasil penyebaran kuisioner diolah untuk menentukan atau menilai kategori proses yaitu $\mathrm{P}(\mathrm{P}$ artically archieved), $\mathrm{L}$ (largely archieved $), \mathrm{F}$ (Fully achieved $), \mathrm{N}$ (Not achieved $)$ [3].

Pembuatan model manajemen risiko dimulai dengan melakukan identifikasi terhadap temuan risiko dari hasil pengolahan kuisioner serta menganalisis untuk menentukan dampak yang diakibatkan dari temuan risiko dan menilai risiko untuk memetakan kategori risiko kedalam tingkat risiko High, Medium, dan Low[4]. Tahap berikutnya adalah mengelola risiko untuk menentukan strategi yang tepat dalam penanganan risiko agar tidak berdampak merugikan terhadap perguruan tinggi. Hasil dari pembuatan rancangan model manajemen risiko diuji untuk memperoleh nilai kelayakan agar dapat diterapkan perguruan tinggi untuk meningkatkan (improvement) layanan pengunduran diri mahasiswa. 


\section{Hasil dan Pembahasan}

\subsection{Pengolahan Hasil Kuisioner}

Pengolahan dilakukan dari hasil penyebaran kuisioner terhadap responden yang ada dilingkungan perguruan tinggi yang terlibat dan bertanggung jawab terhadap layanan pengunduran diri mahasiswa. Adapun pembahasan mengenail kategori proses yaitu :

a. N, kegiatanan/proses ini tidak ada atau hanya sedikit bukti atas pencapaian proses yang sudah berjalan. $(0-15 \%)$

b. P, kegiatan /proses yang sudah berjalan (15-50\%)

c. L, kegiatan /proses yang sudah berjalan $(50-85 \%)$

d. F, kegiatan/proses yang sudah berjalan (85-100\%)

Tabel 1. Data hasil perhitungan kuisioner

\begin{tabular}{|c|c|c|c|c|}
\hline \multirow{2}{*}{ Proses } & \multicolumn{4}{|c|}{ Kategori Proses (\%) } \\
\hline & $\mathbf{P}$ & $\mathbf{L}$ & $F$ & $\mathbf{N}$ \\
\hline APO12.01 & 0,14 & 0,11 & 0,02 & 0,73 \\
\hline APO12.02 & 0,43 & 0,17 & 0 & 0,40 \\
\hline APO12.03 & 0,54 & 0,38 & 0 & 0,08 \\
\hline APO12.04 & 0,50 & 0,14 & 0 & 0,36 \\
\hline APO12.05 & 0,43 & 0,07 & 0 & 0,50 \\
\hline
\end{tabular}

Dari tabel diatas dapat kita ketahui nialai kategori proses untuk setiap aktivitas yang ada pada proses APO12.

\subsection{Identifikasi Risiko}

Tabel 2 merupakan temuan risiko terhadap hasil identifikasi setiap aktivitas proses APO12 sesuai dengan hasil perhitungan kuisioner.

\begin{tabular}{|c|c|c|}
\hline Proses & $\begin{array}{l}\text { Kode } \\
\text { Risiko }\end{array}$ & Temuan Risiko \\
\hline \multirow{2}{*}{$\begin{array}{c}\text { APO12.01 } \\
(\text { Collect Data })\end{array}$} & $\mathrm{R} 1$ & $\begin{array}{l}\text { a. Belum adanya kegiatan untuk mengumpulkan dan } \\
\text { mengidentifikasi isu-isu terkait risiko yang muncul pada } \\
\text { layanan pengunduran diri mahasiswa. }\end{array}$ \\
\hline & R2 & $\begin{array}{l}\text { b. Adanya kegiatan penyampaian informasi mengenai } \\
\text { proses pengunduran diri mahasiswa yang belum } \\
\text { menyeluruh. }\end{array}$ \\
\hline $\begin{array}{c}\text { APO12.02 } \\
\text { (Analysis Risk) }\end{array}$ & R3 & $\begin{array}{l}\text { Belum adanya kegiatan untuk menganalisis risiko dan } \\
\text { dampak yang ditimbulkan dari risiko yang muncul pada } \\
\text { layanan pengunduran diri mahasiswa. }\end{array}$ \\
\hline $\begin{array}{l}\text { APO12.03 } \\
\text { (Articulate Risk) }\end{array}$ & $\mathrm{R} 4$ & $\begin{array}{l}\text { Belum adanya kegiatan pengelolaan risiko dan pengelolaan } \\
\text { dari dampak yang ditimbulkan dari risiko yang muncul pada } \\
\text { layanan pengunduran diri mahasiswa. }\end{array}$ \\
\hline \multirow{2}{*}{$\begin{array}{l}\text { APO12.04 } \\
\text { (Maintain a Risk } \\
\text { Profile Articulate } \\
\quad \text { Risk) }\end{array}$} & R5 & $\begin{array}{l}\text { a. Belum adanyan laporan terkait hasil analisis dan } \\
\text { pengelolaan risiko untuk semua entitas terhadap layanan } \\
\text { pengunduran diri mahasiswa. }\end{array}$ \\
\hline & R6 & $\begin{array}{l}\text { b. Belum adanya kegiatan peninjauan hasil pengelolaan } \\
\text { risiko. }\end{array}$ \\
\hline $\begin{array}{c}\text { APO12.05 } \\
\text { (Define a Risk } \\
\text { Management } \\
\text { Action Portofolio) }\end{array}$ & R7 & $\begin{array}{l}\text { Belum adanya kegiatan pembuatan usulan/ proposal untuk } \\
\text { menangani risiko pada layanan pengunduran diri mahasiswa. }\end{array}$ \\
\hline
\end{tabular}

\subsection{Analisis Risiko}

Kegiatan analisis risiko bertujuan untuk mencari dampak dari risiko, sehingga dapat dilakukan pengukuran terhadak dampat yang akan menentukan kategori temuan risiko. Dan pengukuran akan mempermudah dalam menentukan risiko yang yang harus ditangani terlebih dahulu. Tabel 3 merupakan hasil analisis dan penilaian risiko terhadap temuan risiko hasil identifikasi. 
Tabel 3. Hasil analisis dan penilaian risiko layanan pengunduran diri mahasiswa

\begin{tabular}{|l|l|l|}
\hline $\begin{array}{c}\text { Kode } \\
\text { Risiko }\end{array}$ & \multicolumn{1}{|c|}{ Dampak Risiko } & \multicolumn{1}{|c|}{\begin{tabular}{c}
\multicolumn{1}{|c|}{ Kategori } \\
Risiko
\end{tabular}} \\
\hline R1 & Strategi dalam pengelolaan risiko tidak terstruktur. & High \\
\hline R2 & Tidak tercapainya tujuan layanan yang efektif. & High \\
\hline R3 & $\begin{array}{l}\text { a. Risiko mempengaruhi kinerja organisasi dalam pengambilan } \\
\text { keputusan. } \\
\text { b. Risiko akan mengahambat perkembangan informasi. }\end{array}$ & Medium \\
\hline R4 & Risiko akan menurunkan nilai optimal layanan. & Medium \\
\hline R5 & $\begin{array}{l}\text { Tidak adanya pengukuran kinerja pada kegiatan pengunduran diri yang } \\
\text { akan mempengaruhi keputusan. }\end{array}$ & Low \\
\hline R6 & Terhambatnya kinerja organisasi terhadap suatu layanan. & Low \\
\hline R7 & $\begin{array}{l}\text { a. Tidak terselesaikannya risiko pada pengelolaan layanan. } \\
\text { b. Sulitnya pengendalian risiko yang berpotensi ancaman. }\end{array}$ & Medium \\
\hline
\end{tabular}

\subsection{Mengelola Risiko}

Mengelola Risiko bertujuan untuk menentukan strategi yang tepat dalam menangani risiko dengan bantuan TI berdasarkan proses APO12. Tabel 4 merupakan strategi atau model penangan risiko.

Tabel 4. Model Penanganan Risiko

\begin{tabular}{|c|c|c|}
\hline $\begin{array}{c}\text { Kode } \\
\text { Risiko }\end{array}$ & Penanganan Risiko & Kegiatan Penanganan \\
\hline $\mathrm{R} 1$ & $\begin{array}{l}\text { a. Mengidentifikasi } \\
\text { setiap aktivitas } \\
\text { yang mendukung } \\
\text { jalannya layanan } \\
\text { pengunduran diri. } \\
\text { b. Mengidentifikasi } \\
\text { risiko pada layanan } \\
\text { pengunduran diri } \\
\text { mahasiswa. }\end{array}$ & $\begin{array}{l}\text { a. Mendefinisikan kebutuhan-kebutuhan data terkait } \\
\text { dalam proses pengunduran diri mahasiswa. } \\
\text { b. Proses/ kegiatan pengunduran diri dengan bantuan } \\
\text { portal akademik: } \\
\text { - Menyiapkan modul pengunduran diri } \\
\text { - Menyediakan formulir permohonan pengunduran diri } \\
\text { online. } \\
\text { - Mahasiswa melakukan pengisian data pada formulis } \\
\text { permohonan pengunduran diri. } \\
\text { - Kaur transaksi akademik melakukan upload surat } \\
\text { pengunduran diri pada sistem portal akademik. } \\
\text { c. Mengidentifikasi kelemahan-kelemahan pada data } \\
\text { pengunduran diri. } \\
\text { d. Mengidentifikasi kemelemahan pada proses } \\
\text { pengumpulan data pengunduran diri. }\end{array}$ \\
\hline R2 & $\begin{array}{l}\text { a. } \\
\text { Membuat alur/ } \\
\text { flowchart kegiatan } \\
\text { pengunduran diri } \\
\text { mahasiswa. } \\
\text { b. Memberikan } \\
\text { pengarahan } \\
\text { mengenai proses- } \\
\text { proses yang harus } \\
\text { dilakukan dalam } \\
\text { pengunduran diri } \\
\text { mahasiswa. }\end{array}$ & $\begin{array}{l}\text { a. Menambahkan fitur layanan pengunduran diri } \\
\text { mahasiswa pada sistem portal akademik untuk } \\
\text { mendeskripsikan alur/ flowchart pengunduran diri } \\
\text { mahasiswa. } \\
\text { b. Pengarahan proses pengunduran diri dapat di tampilkan } \\
\text { pada chanel media seperti TV yang ada disetiap } \\
\text { fakultas. }\end{array}$ \\
\hline R3 &  & $\begin{array}{l}\text { a. Menganalisis kelemahan data pengunduran diri. Hasil } \\
\text { analisis kelemahan data serta dampak yang } \\
\text { ditimbulkan: } \\
\text { 1. Sulitnya memperoleh surat keterangan bebas } \\
\text { (perpustakaan, laboratorium, dan keuangan), } \\
\text { menyebabkan proses pengunduran diri berjalan } \\
\text { lambat. } \\
\text { 2. Sulitnya memperpoleh tanda pengesahan dari } \\
\text { (Dosen Wali, Dekan, dan Kaprodi), menyebabkan } \\
\text { proses pengunduran diri berjalan lambat. }\end{array}$ \\
\hline
\end{tabular}




\begin{tabular}{|c|c|c|}
\hline & $\begin{array}{l}\text { terhadap layanan } \\
\text { pengunduran diri. }\end{array}$ & $\begin{array}{l}\text { b. Menganalisis kelemahan pada proses pengumpulan } \\
\text { data. Hasil analisis proses pengumpulan data serta } \\
\text { dampak yang ditimbulkan: } \\
\text { 1. Surat permohonan tidak diserahkan kepada BAA } \\
\text { oleh pemohon (mahasiswa), menyebabkan } \\
\text { mahasiswa tidak memperoleh SK dari Rektor dan } \\
\text { layanan pengunduran diri tidak berjalan seacara } \\
\text { optimal. } \\
\text { 2. Penggunaan sistem informasi akademik portal yang } \\
\text { sangat minim/ jarang oleh Dosen, Dekan, dan } \\
\text { Kaprodi, menyebabkan dosen tidak mengetahui } \\
\text { keterlibatannya dalam proses pengunduran diri. } \\
\text { Menganalisis kelemahan pada saat upload surat } \\
\text { pengunduran diri. Hasil analisis proses upload: } \\
\text { 1. Format surat yang tidak sesuai kebutuhan data, } \\
\text { menyebabkan surat tidak dapat diupload sehingga } \\
\text { perlu mengubah format surat. } \\
\text { 2. Membutuhkan database yang cukup besar untuk } \\
\text { menyimpan data arsip mahasiswa yang } \\
\text { mengundurkan diri. }\end{array}$ \\
\hline $\mathrm{R} 4$ & $\begin{array}{l}\text { Menentukan strategi } \\
\text { yang tepat untuk } \\
\text { mengelola risiko pada } \\
\text { layanan pengunduran } \\
\text { diri mahasiswa. }\end{array}$ & $\begin{array}{l}\text { a. Menambahkan layanan pengunduran diri pada sistem } \\
\text { portal akademik supaya proses pengunduran diri } \\
\text { berjalan seperti yang diharapkan. } \\
\text { b. Pada pemenuhan surat keterangan bebas dapat dibuat } \\
\text { link ke sistem yang ada di laboratoium, perpustakaan, } \\
\text { dan keuangan. } \\
\text { c. Adanya pemberitahuan melalui notifikasi dan email, } \\
\text { serta dengan menghubungi pihak yang terlibat dalam } \\
\text { pengesahan permohonan. } \\
\text { d. Memberikan pengarahan mengenai bentuk/ format } \\
\text { dokumen pada saat akan melakukan upload surat } \\
\text { pengunduran diri. } \\
\text { e. Mepersiapkan database dalam skala besar untuk } \\
\text { menyimpan arsip mahasiswa yang mengundurkan diri } \\
\text { pada sistem portal akademik. }\end{array}$ \\
\hline R5 & \begin{tabular}{|l} 
a. \\
Mempersiapkan \\
modul \\
pengembangan \\
layanan yang dapat \\
mendukung dalam \\
pengingkatan \\
layanan \\
pengunduran diri. \\
b. Membuat \\
dokumentasi dari \\
hasil pengelolaan \\
risiko.
\end{tabular} & $\begin{array}{l}\text { Memelihara kesiapan dari sistem portal akademik agar } \\
\text { dapat digunakan dalam proses pengunduran diri. } \\
\text { - Menyelaraskan kegiatan proses pengunduran diri online } \\
\text { dengan proses bisnis yang sesuai dengan SOP. } \\
\text { - Melakukan testing/ pengujian terhadap kegiatan } \\
\text { pengunduran diri online. } \\
\text { - Melakukan peninjauan dan pengelolaan sistem portal } \\
\text { akademik khususnya proses pengunduran diri online } \\
\text { secara berkesinambungan. } \\
\text { - Mendokumentasikan hasil dari peninjauan dan } \\
\text { pengelolaan terkait proses pengunduran diri online. }\end{array}$ \\
\hline R6 & $\begin{array}{l}\text { Membentuk tim/ } \\
\text { menentukan pihak } \\
\text { yang bertanggung } \\
\text { jawab atas } \\
\text { keterlibatannya dalam } \\
\text { proses pengunduran } \\
\text { diri mahasiswa untuk } \\
\text { dapat melakukan } \\
\text { kegiatan peninjauan, } \\
\text { pengelolaan, serta } \\
\text { pengembangan. }\end{array}$ & $\begin{array}{l}\text { Menentukan penanggung jawab. } \\
\text { - Dekan, Kaprodi dan Dosen Wali selaku penyelenggara } \\
\text { untuk dapat melakukan peninjauan serta melaporkan } \\
\text { mengenai temuan masalah/ risiko yang ditemukan } \\
\text { kepada BAA. } \\
\text { - BAA selaku pengelola layanan akademik bertanggung } \\
\text { jawab untuk melakukan perubahan atau perbaikan pada } \\
\text { layanan pengunduran diri agar dapat menangani risiko } \\
\text { serta bekerja sama dengan Biskom untuk melakukan } \\
\text { pengembangan. }\end{array}$ \\
\hline
\end{tabular}




\begin{tabular}{|c|c|c|}
\hline & & $\begin{array}{l}\text { - Biskom selaku pengembangan sistem portal akademik } \\
\text { yang betranggung jawab atas perbaikan dan } \\
\text { pengembangan sistem portal akademik. }\end{array}$ \\
\hline R7 & $\begin{array}{l}\text { Membuat usulan/ } \\
\text { proposal untuk } \\
\text { pencegahan dan } \\
\text { penanganan risiko. }\end{array}$ & $\begin{array}{l}\text { a. Dosen Wali, Kaprodi, dan Dekan (pihak pertama) } \\
\text { melakukan pengamatan terhadap jalannya pengunduran } \\
\text { diri. } \\
\text { b. Pihak pertama melaporkan mengenai hasil pengamatan } \\
\text { kepada BAA. } \\
\text { c. Apabila terdapat indikasi risiko, maka BAA melakukan } \\
\text { pengamatan ulang untuk mendeskripsikan mengenai } \\
\text { risiko yang akan terjadi pada pengunduran diri } \\
\text { mahasiswa. } \\
\text { d. BAA melakukan analisa hasil pengamatan terhadap } \\
\text { risiko serta dampak yang akan ditimbulkan dari risiko } \\
\text { tersebut. } \\
\text { e. BAA melakukan pengelolaan risiko untuk menangani } \\
\text { risiko. } \\
\text { f. BAA membuat alur penanganan risiko dan } \\
\text { mensimulasikan alur penanganan untuk mengukur } \\
\text { tingkat keberhasilan penanganan risiko. } \\
\text { g. BAA mengimplementasikan hasil penanganan risiko. } \\
\text { h. BAA melakukan evaluasi terhadap pengelolaan risiko. } \\
\text { i. BAA melaporkan hasil evaluasi penanganan risiko. }\end{array}$ \\
\hline
\end{tabular}

\subsection{Uji Validasi Model Penanganan Risiko}

Uji validasi model dilakukan kepada 3 responden yang ada di BAA yaitu Kabid AEA, Ka Ur transaksi akademik dan Ka Ur evaluasi transaksi akademik. Akademik hasil perhitungan kuisioner uji validasi yaitu :

$$
\begin{aligned}
& \text { Sesuai }=\frac{48}{2 \times 25} \times 100 \%=0,96 \% \\
& \text { Tidak Sesuai }=\frac{2}{2 \times 25} \times 100 \%=0,04 \%
\end{aligned}
$$

Dari hasil kuisioner yang diberikan kepada jawaban, yang menyatakan sesuai sebanyak $0,96 \%$ dan tidak sesuai $0,04 \%$. Artinya model yang diusulkan secara garis besar dapat di terapkan untuk meningkatkan layanan pengunduran diri mahasiswa di perguruan tinggi.

\section{Kesimpulan}

Pada penelitian ini menghasilkan:

1) Diperoleh data hasil identifikasi terhadap hasil perhitungan kuisioner untuk tiap-tiap aktivitas APO12 yaitu untuk aktivitas APO12.01 diperoleh nilai tertinggi yaitu $0.73 \%$ berada pada kategori $\mathrm{N}$ yang menunjukan proses pengumpulan data mengenai risiko belum dilaksanakan. Aktivitas APO12.02 diperoleh nilai tertinggi yaitu $0.40 \%$ pada kategori $\mathrm{N}$ yang menunjukan kegiatan menganalisis risiko belum dilaksanakan dan $0.43 \%$ pada kategori $\mathrm{P}$ menunjukan kegiatan menganalisis risiko sudah dilaksanakan namun masih bersifat rendah. Aktivitas APO12.03 diperoleh nilai tertinggi yaitu $0.54 \%$ pada kategori P yang menunjukan kegiatan mengelola profil risiko belum terlaksana dengan baik. Aktivitas APO12.04 diperoleh nilai tertinggi yaitu $0.50 \%$ pada kategori $\mathrm{P}$ yang menunjukan kegiatan mengartikulasikan risiko belum terlaksana dengan baik. Aktivitas APO12.05 diperoleh nilai tertinggi $0.57 \%$ pada kategori $\mathrm{N}$ yang menunjukan kegiatan mendiefinisikan tindakan portofolio belum dilaksanakan dan sebanyak 0,43\% menyatakan kegiatan sudah dilaksanakan namun belum maksimal.

2) Telah diperoleh 7 temuan risko beserta dampaknya dari hasil analisis terhadap layanan pengunduran diri mahasiswa yang menunjukan bahwa temuan risiko R1 dan R2 kategori risiko High, R3, R4 dan R7 kategori risiko Medium, R6 dan R5 kategori risiko Low. 


\section{Daftar Pustaka}

[1] Ahmad, A dan Handayaningsih, S. 2012. Pengukuran Tingkat Kesuksesan Sistem Informasi Akademik Universitas XYZ Dengan Model Delone Dan Mclean.

[2] Nurfadlun. 2017. Pembuatan Model Manajemen Risiko Pada Pengelolaan Infrastruktur Teknologi Informasi Menggunakan Frameowrk COBIT 5 Di Biskom UAD. Skripsi. Yogyakarta: Teknik Informatika UAD.

[3] Rizkia, Fajrin. 2014. Evaluasi Tata Kelola Teknologi Informasi Menggunakan Framework Cobit 5 Fokus Pada Proses Manage Relationship APO08. Skripsi. Jakarta: Sains Dan Teknologi UIN.

[4] Noviyanto. 2013. Manajemen Teknologi Informasi(Studi Kasus Badan Pusat Statistik). Jurnal Teknik Elektro Dan Informatika. Institut Teknologi Bandung.

[5] Ayu, N dan Putu, G. 2016. Analisis Manajemen Risiko Pada Sistem Akademik Di STIMIK STIKOM Bali, Seminar Nasional Teknologi Informasi dan Multimedia. ISSN: 21023805.

[6] Gilang, M dan Victor, R. 2015. Analisisi Manajemen Resiko Teknologi Informasi Penerapan Pada Document Management System Di PT. Jabar Telematika (JATEL).

[7] Putra, N. 2014. Evaluasi Tata Kelola Teknologi Informasi Pada Sistem Pendidikan Jarak Jauh Menggunakan Framework COBIT 5. Skripsi. Jakarta: Sains Dan Teknologi UIN. 